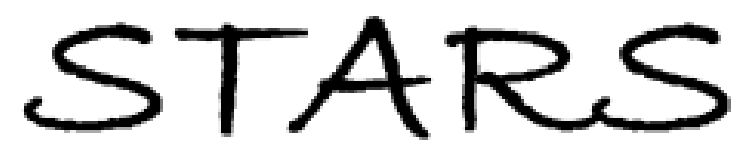

University of Central Florida

STARS

$1-1-2004$

\title{
Hurricane loss estimation models - Opportunities for improving the state of the art
}

Charles C. Watson Jr.

Mark E. Johnson

University of Central Florida

Find similar works at: https://stars.library.ucf.edu/facultybib2000 University of Central Florida Libraries http://library.ucf.edu

This Article is brought to you for free and open access by the Faculty Bibliography at STARS. It has been accepted for inclusion in Faculty Bibliography 2000 s by an authorized administrator of STARS. For more information, please contact STARS@ucf.edu.

\section{Recommended Citation}

Watson, Charles C. Jr. and Johnson, Mark E., "Hurricane loss estimation models - Opportunities for improving the state of the art" (2004). Faculty Bibliography 2000s. 4873.

https://stars.library.ucf.edu/facultybib2000/4873

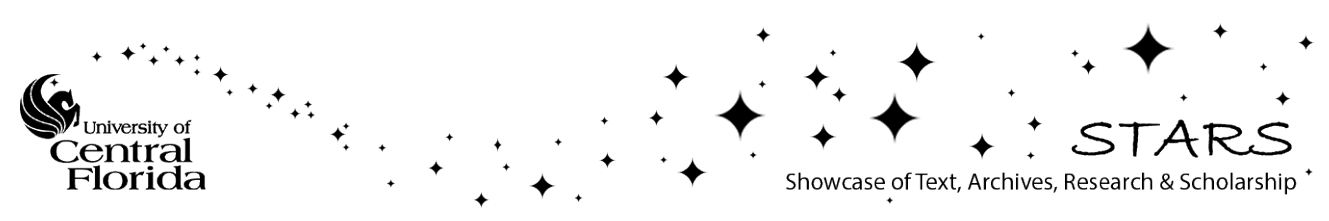




\title{
HURRICANE LOSS ESTIMATION MODELS Opportunities for Improving the State of the Art
}

\author{
by Charles C. Watson Jr. and Mark E. Johnson
}

\begin{abstract}
Hurricane loss models, in particular, the wind models and historical hurricane parameters, must be improved before users and regulators can apply these models with confidence.
\end{abstract}

N umerical hurricane loss models have become widely used in the insurance industry as a tool for determining loss costs. Loss cost is defined as the annualized dollar amount of loss a given exposure will suffer over time, in other words, how much money must be set aside each year to offset losses for a given exposure. Loss costs are used as the basis for establishing the premiums to be paid by the consumer. The models presently in use in the insurance industry are proprietary, which raises difficult issues for state insurance regulators charged with assuring that rates are fair, reasonable, and nondiscriminatory. There is a need to establish the limitations and performance of these models in an objective manner to provide users of loss-costs data with an understanding of the technology, especially given that the inner workings of the models are not available to general users (those who have not executed confidentiality

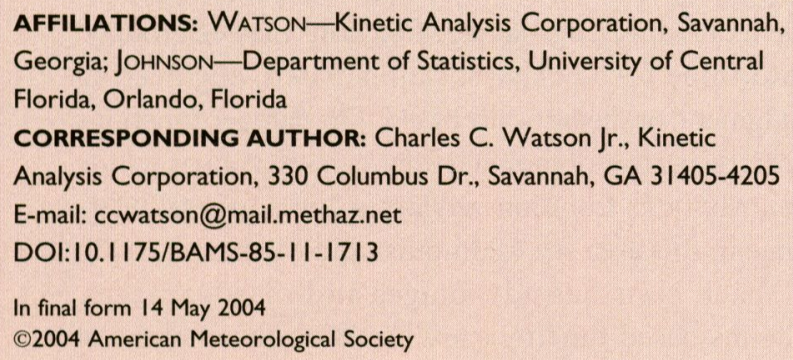

agreements). Moreover, the sheer complexity of the models makes it difficult even for a sophisticated user to accomplish a proper evaluation. This paper reports the results of a comprehensive study of loss costs conducted under the sponsorship of the North Carolina Department of Insurance (Watson and Johnson 2003, available online at www.methaz.com/ncdoi/). The objectives of the study were to create an assessment of the "state of the art" of loss modeling, create a dataset of losses for North Carolina, and to create a method for evaluating individual model results as might be received in insurance rate filings.

The basic approach was to identify nine wind models, four surface friction models, and nine damage models drawn from the published literature (meteorology, engineering, and insurance) leading to 324 combinations of models. Each of these combinations was assessed against hurricane losses reported by a major insurance company. Annual loss costs were then computed using these 324 combinations of models for both North Carolina and Florida, and compared with publicly available proprietary model results in Florida. As is shown here, there is a considerable need to improve these models. Although this study did not formally establish a baseline reference model (Pielke et al. 1999), the "simple" models (such as based on the Rankine Vortex wind model) with no adjustments for terrain performed as well as more complex combinations. 
OVERVIEW OF LOSS MODELS. Hurricane loss models generally consist of five major components:

1) input databases;

2) wind model;

3) boundary layer (surface friction and topography) model;

4) damage or vulnerability function;

5) frequency of occurrence model.

Each of these components is described in turn.

Input databases. All models use a minimum of three input datasets: land cover, historical storm tracks, and an exposure dataset. Some models also use digital elevation models as well, and the level of detail required in the land cover, track, and exposure datasets can vary greatly depending on the needs of the model. For example, the most basic land cover model can simply indicate if a given location is land or sea. A more advanced land cover model, such as the one used in the trajectory-based model, consists of 72 land cover classifications, each with values for aerodynamic friction and debris-generating potential. Input datasets should use timely data, and be matched to the models that use them.

Exposure datasets can contain not only the location and value of the risk, but the construction type and even effectiveness of code enforcement, which can greatly influence the extent of damage. For estimating total losses from an individual storm, the complete ensemble of construction types may be unknown so that modelers build datasets of the typical mix of construction in a given area-in other words, the percentage of wood frame, concrete block, or mobile homes in an area. It is important that the spatial characteristics of the exposure and the land cover datasets match. For example, a zip code-level exposure dataset that treats zip codes as points should not use a land cover dataset at a vastly higher resolution (much less than the width of a typical zip code-say a mile or two), as the land cover at the exact point in which the centroid falls may not be representative of the land cover of the zip code.

For both the simulation of historical events and the determination of frequency of occurrence, a library of historical hurricane tracks and intensities is required. The U.S. National Hurricane Center maintains a library of historical storms, called the North Atlantic hurricane database (HURDAT) [Jarvinen et al. 1984), with updates through Landsea et al. $(2004 a, b)]$. This dataset, available through their Web and FTP sites, is updated annually, and currently con- tains tracks for the years 1851 through 2002. It is important to obtain the annual updates, as the National Hurricane Center not only updates each year's new storms, but is conducting an extensive reanalysis of historical storms and has revised many older tracks [and not so old, as the revision last year of Andrew (1992) to a category-5 storm indicates]. The sidebar provides an analysis of the impact of the reanalysis on damages produced by simple wind models.

Wind models. As with land cover models, wind models range from the extremely simple Rankine Vortex to complex parametric models to full three-dimensional physics models. Virtually all of the models in use in the insurance loss modeling field are parametric models using simple storm parameters such as the minimum central pressure, radius of maximum winds, forward speed, and so forth. Wind models may produce the wind at the surface or a gradient wind (a wind at some altitude above the surface, generally considered to be the top of the boundary layer-in a hurricane, perhaps $1000 \mathrm{~m}$ above the terrain). Gradient winds are stronger than surface winds due to friction effects, whereas a surface wind already includes some of this correction. Table 1 provides brief descriptions of the nine wind field models considered in this study.

Boundary layer (surface friction). The raw winds produced by a parametric wind model usually need to be corrected for surface conditions. The simplest method for correcting winds to the surface is by a single multiplication factor. There is much debate in the literature as to the correct factor, with values over water generally about 0.85 , and over land 0.7 , but values from 0.5 to 1.1 have been suggested under various circumstances. More complex models use unique factors for different terrain types, while the most sophisticated models analyze the trajectory of the wind to include both upstream land cover and topography, to include ridge and valley effects (see Table 2).

Damage functions. The damage function (also called the vulnerability or loss function) relates the wind deposited on a site to the damage expected at the site. Generally speaking, damage functions may be grouped into three broad classes: claims-based, engineering judgment, or theoretically based. The damage functions are irrespective of monetary damages that also include contributions from insured losses. For a general reference in this area see Malmquist and Michaels (2000).

Each class has advantages and disadvantages. Claims-based functions are based on the analysis of actual claims submitted to insurance companies. 
An interesting situation has been created with respect to Hurricane Andrew (1992). Andrew is probably one of the best-observed modern storms with respect to damage surveys. Many modelers have stated in their submissions and in publications that they used computed winds in conjunction with reported damages from Andrew to construct their damage functions, as well as for use in their validation studies and in their public marketing efforts. The National Hurricane Center (NHC) has recently changed the official "best fit" maximum wind speed during the Florida landfall from 125 to $145 \mathrm{kt}$ (Landsea et al. 2004b). Depending on the combination of wind and damage functions used, as well as the method used to convert the HURDAT track into a track for use in a loss simulation, this could result in significant changes to the simulated damages from this event. Table SBI, below, shows the results of simulations using the original intensity versus using the revised intensities for our alpha, beta, gamma, and delta models. For these simulations, we limited the comparison to losses in 71 zip codes in the Florida landfall, from a single insurance company. It is worth noting that 274 of the 324 model combinations produced results closer to the reported loss using the revised track.

During the process of conducting these simulations, one fact became clear: apparently minor design and input data decisions can have significant impacts on computed losses. For example, it is widely assumed in many simulations that the ambient environmental (far field) pressure for hurricanes can be taken as a fixed value of $1013 \mathrm{mb}$, with the pressure drop (and wind speed) computed using this fixed value. The 1013 value is assumed in the Florida Commission proceedings, and the working assumption has been that this value has little impact on the final loss totals. However, an analysis of the $\mathrm{NHC}$ data for storms between 1990 and 2001 reveals that the median is $1012 \mathrm{mb}$. To assess the impact of a $\mathrm{I}-\mathrm{mb}$ change in the assumed environmental pressure, two sets of "Form B" simulations were made using the alpha model, holding all other factors constant. The aggregate dollar value loss for the 1013-mb run was $\$ 3,488,065$, while the $1012-\mathrm{mb}$ run was $6.7 \%$ less, at $\$ 3,253,168$. The results for all 30 simulations, expressed as a percent difference from the $1012-\mathrm{mb}$ run, are shown in Fig. SBI. For the category-I events, the differences in overall losses are an astonishing $20 \%$ or more! Of course, we expect the greatest sensitivity to occur for the weak storms since a I-mb adjustment has the greatest influence on the pressure difference. Even for the stronger category- 3 events, differences in losses range between $6 \%$ and $8 \%$ higher for a far-field pressure of 1013 versus $1012 \mathrm{mb}$. For category-5 events, the far-field pressure appears less influential, but still results in significant dollar value differences due to the large losses inflicted by these storms. Overall, a $\mathrm{I}-\mathrm{mb}$ difference in the assumed environmental pressure would result in a $5 \%$ change in the loss cost (and therefore

\begin{tabular}{|lcc|}
\hline \multicolumn{3}{|c|}{$\begin{array}{c}\text { TABLE SB I. Impact of Hurricane } \\
\text { revision }\end{array}$ on loss calculations. } \\
\hline Model & $\begin{array}{c}\text { Percent difference } \\
\text { (original track) }\end{array}$ & $\begin{array}{c}\text { Percent difference } \\
\text { (revised track) }\end{array}$ \\
\hline Alpha & -15.2 & +0.9 \\
\hline Beta & -18.2 & +1.0 \\
\hline Gamma & -32.3 & -1.0 \\
\hline Delta & -21.0 & +3.0 \\
\hline
\end{tabular}

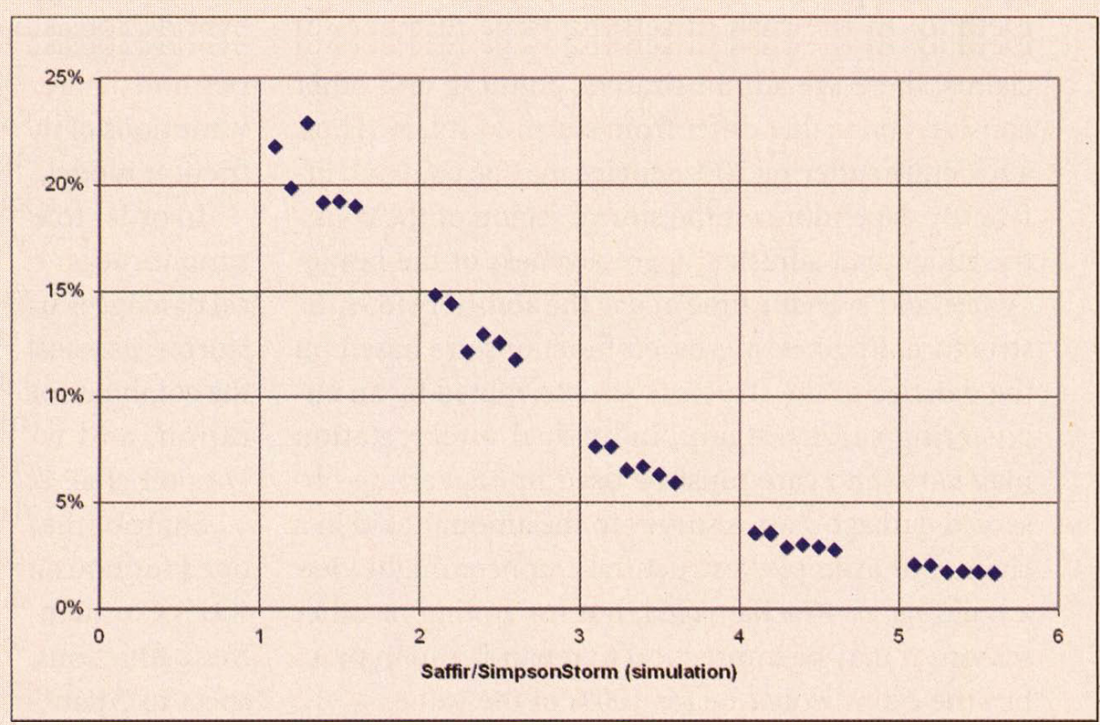

FIG. SBI. Percent difference in losses assuming $1012-$ vs $1013-\mathrm{mb}$ farfield pressure. premium paid by the consumer) using this model, which is representative of those used in the insurance industry.

This experiment also demonstrates the extreme sensitivity of the damage models to small changes in wind speeds, due to the exponential nature of damage functions. The peak wind speed difference between simulations of a given wind speed was approximately I kt, with the average difference being $0.75 \mathrm{kt}$. Given the uncertainty in all parameters concerning tropical cyclones, the current generation of loss models appears to be far too sensitive to input parameters. In addition, this exercise further demonstrates the dangers of tuning models to specific storms, as the understanding of the intensity of the storm may change with new data or better analytical techniques. 
TABLE I. The wind fields used in the study. Intensity basis indicates the model uses the reported peak wind (Vmax), the pressure difference (delta P), or both (hybrid) to compute winds. Surface/gradient indicates if the model computes surface winds directly, or computes a gradient wind that must be adjusted to the surface. Other parameters commonly used are the radius to maximum winds, environmental or far field pressure, and radius to the environment or far field. Forward speed and direction are also used but not included in the parameter count.

\begin{tabular}{|l|l|c|c|c|}
\hline $\begin{array}{l}\text { Wind field } \\
\text { (abbreviation) }\end{array}$ & Reference & $\begin{array}{c}\text { No. key } \\
\text { parameters }\end{array}$ & $\begin{array}{c}\text { Intensity } \\
\text { basis }\end{array}$ & $\begin{array}{c}\text { Surfacel } \\
\text { gradient }\end{array}$ \\
\hline $\begin{array}{l}\text { U.S. Air Force Global } \\
\text { Weather Command (AFGWC) }\end{array}$ & Brand et al. (1977) & 4 & $V$ max & Surface \\
\hline Standard project hurricane (SP) & Schwerdt et al. (1979) & 3 & Delta $P$ & Gradient \\
\hline Miller (MI) & Miller (1962) & 3 & $V$ max & Either \\
\hline Holton (HN) & Holton (1992) & 3 & $V$ max & Either \\
\hline Rankine Vortex (RV) & $\begin{array}{l}\text { Coastal Engineering Research } \\
\text { Center (1984) }\end{array}$ & 2 & $V$ max & Either \\
\hline Bretschneider (BR) & Bretschneider (1972) & 3 & Vmax & Gradient \\
\hline $\begin{array}{l}\text { Sea, land, and oversea surges } \\
\text { from hurricane phenomena (SL) }\end{array}$ & Jelesnianski et al. (1992) & 2 or 3 & Delta $P$ & Hybrid \\
\hline
\end{tabular}

TABLE 2. Four surface friction models were used to adjust wind speeds due to surface affects.

\begin{tabular}{|l|l|l|}
\hline \multicolumn{1}{|c|}{ Method (abbr.) } & \multicolumn{1}{|c|}{ Reference } & \multicolumn{1}{c|}{ Key aspect of method } \\
\hline No adjustment (NO) & Schwerdt et al. (1979) & Two wind values (over land; over water) \\
\hline Cell (CE) & Cook (1985) & Adjusted according to land cover in cell \\
\hline $\begin{array}{l}\text { American Society of } \\
\text { Civil Engineers (ASCE)(AS) }\end{array}$ & ASCE (2000) & Follows method given in ASCE-7-98 \\
\hline Trajectory (TR) & Watson (1995) & Wind depends on upwind topography and land cover \\
\hline
\end{tabular}

While at first glance this may seem to be a logical, even optimal approach, there are problems with this method. In the rush of settling large numbers of claims, there are administrative, political, and other considerations that differ from storm to storm. Thus, a structure suffering $20 \%$ damage may be paid out differently depending on the storm, region of the country, individual adjuster, aggressiveness of the homeowner, and even the time of day the adjuster views the structure. Engineering-based functions are based on the damage to the structure as determined by an engineering survey. Again, individual interpretation may vary, and care must be used in converting observed damage from a survey to the amount paid in a claim. For example, a structural engineer might view a building as $40 \%$ damaged, but for zoning or other reasons it may be impractical to repair it and in practice the claim would be for $100 \%$ of the value.

Theoretical functions are based on the physics of the behavior of structures. While this approach reduces the influence of human judgment on the func- tion, the human factors noted above must be categorized and included in some way. Many functions are hybrids, consisting of a mix of the three broad categories noted here. Care must be taken to ensure the assumptions of the wind model, boundary layer/surface friction model, and damage models are compatible.

In order to exploit the full historical storm set, the simplification of relating maximum winds to physical damage is used. Clearly, for well-observed specific storms, physical damage estimates could benefit from the combination of maximum winds, strong wind duration, and wind steadiness (Powell et al. 1995; Dunion et al. 2003).

Some of the damage models (Table 3) were developed for housing stock outside of the Americas (e.g., the Australian damage function). We still include these functions and note their performance with respect to Atlantic basin storms.

Frequency of occurrence. The above components (input database, wind model, friction model, and dam- 
TABLE 3. Damage functions translate the peak wind at the site (or, in the case of the energy-based function, the amount of stress on the structure, which includes the duration of the stress) into the damage to the structure.

\begin{tabular}{|lll|}
\hline Method (abbr.) & Reference & Basis of method \\
\hline Australian (AUS) & Leicester and Beresford (1978) & Damage surveys \\
\hline Foremost (FORM) & Foremost Insurance Co. (1996) & Claims \\
\hline Friedman (FRIED) & Friedman (1984) & Claims \\
\hline Clemson I (CLEMI) & Sill et al. (1997) & Claims, engineering judgment \\
\hline Clemson2 (CLEM2) & Rosowsky et al. 1999 & Claims \\
\hline ProTeam (PT) & FCHLPM (2002) & Engineering judgment \\
\hline X-Cubed (XCUB) & Howard et al. (1972) & Engineering judgment \\
\hline Energy (ENER) & Watson (2002b) & Theoretical \\
\hline Stubbs (STUB) & Stubbs (1996) & Theory, engineering judgment \\
\hline
\end{tabular}

age function) answer the question of the magnitude of the losses for a single given storm track. In order to compute loss costs, the question "how often?" must be answered as well. Therefore the question of frequency arises. Three common approaches are 1) to rely on historical events, 2) fit and smooth probabilities along coastal segments, or 3 ) try to reproduce hurricane formation and movement in a realistic fashion.

Approach 1 presumes that the future tropical cyclone activity will follow that which has occurred previously. Since estimated loss costs apply for the shortterm (imminent) future, long-term climatologic trends would normally not be incorporated (of course, if there were definitive evidence that hurricane incidence and intensity were to spike in the next few years, that is a different matter). The HURDAT database noted earlier covers Atlantic basin events from 1851 through 2002, and includes the recent updates for the period 1886-1910. Since this approach mimics exactly the historical record, it is guaranteed that modeled landfall frequencies match history. This is the approach that is the basis for this paper. We mention other approaches shortly for completeness.

Approach 2 involves taking the historical events and then fitting the frequencies by coastal segments to assure that modeled landfalls closely match the historical record while "smoothing" the results to match what meteorologists might expect in the long term. The smoothing typically follows that given in National Weather Service Report 23 (Schwerdt et al. 1979), which is a weighted average along the coast from a given site.

Approach 3 has been accomplished using two approaches, statistical or using climate models. In the statistical method, future hurricane events are launched from their initiation point in the Atlantic basin according to historical information. A track is then simulated following historical track and intensity progressions such as the Climatology and Persistence (CLIPER) and Statistical Hurricane Intensity Forecast (SHIFOR) models (Hope and Neumann 1970). If these generated tracks are correct (resemble reality), then the landfall frequencies should be appropriate. The second method requires the use of climate models, and is extremely challenging computationally. Other than in experimental research and development efforts, it is not thought to have been used operationally.

Figure 1 shows the historical tracks of tropical cyclones that have impacted North Carolina since 1851, based on the HURDAT database. About 25 hurricanes are included in this figure. It appears that virtually all of the coastal Carolina areas, and many inland areas, have been impacted by the storms' swaths. Here we assume that interest concerns both hurricanes and other tropical events that produce damage in North Carolina. The rationale is that a declared hurricane (such as Hugo) can make landfall in another state and then proceed to inflict damage on North Carolina at a reduced intensity level (subhurricane).

Appropriate landfall frequencies are an essential element in estimating loss costs as the frequency of events goes hand in hand with loss costs (e.g., if frequencies were to increase $10 \%$, one would expect that loss costs would also increase by $10 \%$ as a first approximation). By using the entire HURDAT database, there is a possibility that owing to limited observations in Florida, the occurrence rate may be underestimated (Landsea et al. 2004a). Interestingly, the southwest coast of Florida demonstrates somewhat higher hurricane occurrence when the older (pre-1886) data were included. 


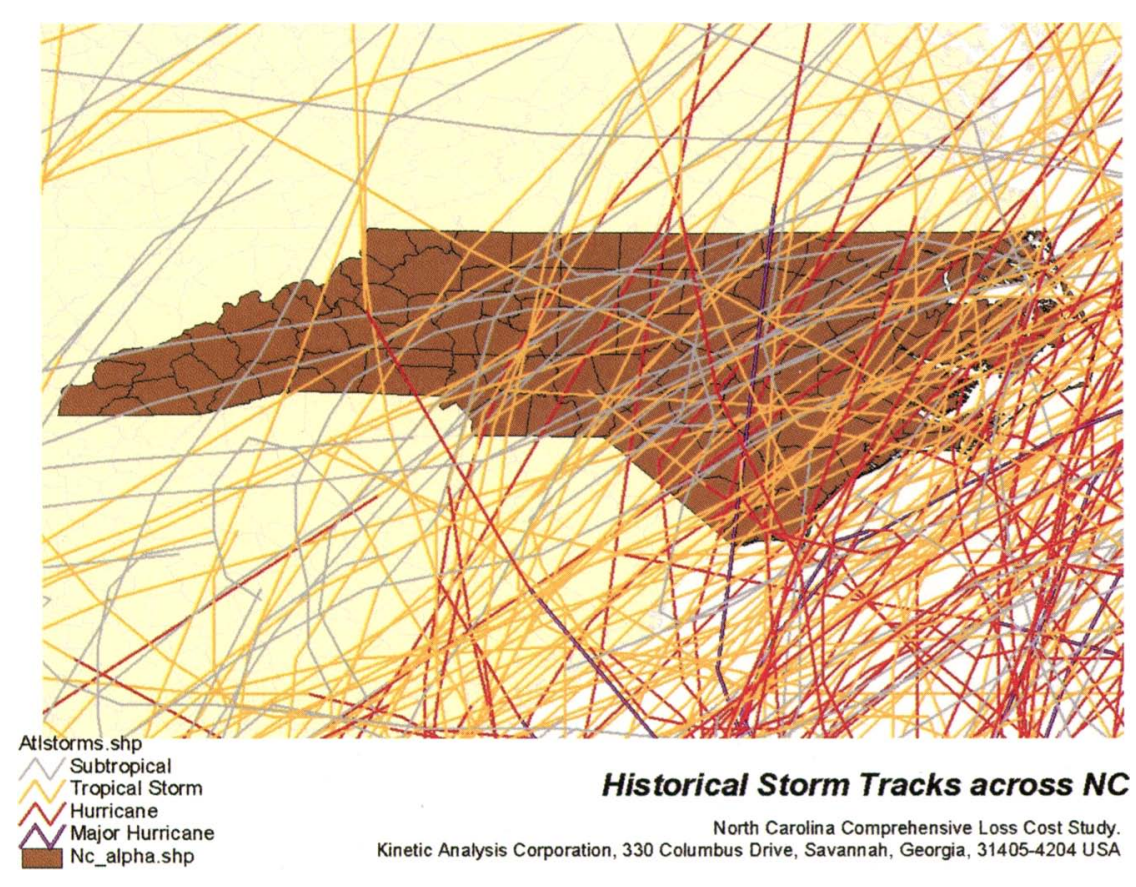

FIG. I. Historical tropical cyclone tracks near North Carolina.

so forth, depending on the specific model). These distributions are then used to simulate a future of 50,000 yr or so of events, accumulating damage for each simulated storm. There are additional variants of sampling methods used by modeling companies that can be gleaned from their public submissions.

MAXIMUM LIKELIHOOD ESTIMATION APPROACH. This approach was developed by the authors of this study to handle wind, wave, and storm surge perils in the Caribbean (Johnson and Watson 1999). In validating this approach, it became apparent that the method

Once the frequencies are estimated, various approaches can be applied to estimate loss costs. We consider three in turn.

Historical storm set estimation. An obvious approach that serves as a reasonable baseline is to simulate the historical storm set based on the current exposure and then divide the loss costs by 152 . Recall that we are using the 1851-2002 HURDAT dataset that constitutes $152 \mathrm{yr}$, including 1288 tropical cyclones. For each of the 324 combinations of public domain (PD) models, we simulate each of the 1288 storms, collecting damage information at the census block group (CB) level for each. Aggregated damage for zip codes is determined from those CBs in the appropriate zip code. Aggregated damage at the county level is determined from those CBs in the appropriate county. Unlike census blocks, which adhere to political boundaries such as cities and counties, zip codes often cross such boundaries. Therefore, some CBs are in a zip code belonging to a county other than the county in which the $\mathrm{CB}$ resides!

Monte Carlo simulation and estimation. An approach popularized by Applied Insurance Research (AIR) in the 1980s and used by other modeling companies fits probability distributions to key characteristics of hurricanes including landfall locations and frequencies and individual hurricane characteristics (central pressure, radius of maximum winds, forward speed, and was applicable throughout the Atlantic basin. Moreover, this approach can be viewed in some respects as a compromise between the historical storm set and Monte Carlo approaches. The starting point is to use the historical storm set and simulate every storm and record the maximum wind from each storm at each site (for this study every CB). Next the set of 1288 data values are reduced to the annual maxima, and the Weibull probability distribution is fit by maximum likelihood estimation (MLE) to the 152 values at each site. The median of the fitted distribution represents next year's most plausible extreme wind that then can be converted to loss costs. For this study we are using the approach solely for a 1-yr forecast, but the method can be used to estimate return periods, as well. Validation data and a further discussion of the MLE Weibull method is contained in the North Carolina Department of Insurance (NCDOI) report, and in Johnson (1997).

Table 4 summarizes the differences and similarities of the three aforementioned approaches. In the NCDOI analysis, we use both the historical and MLE Weibull methods, indicating where necessary which is employed for each upcoming table or figure.

METHODOLOGY. The computer simulations conducted for the study were made using the Wind Damage Prediction and Evaluation Package (WDPEP; Watson 2002a), a program implemented by the authors to compare hurricane wind and loss 
models. All of the techniques used in the program are readily available in the published literature. The latest version of WDPEP includes 12 wind fields, 6 boundary layer models, and 10 damage functions. Some of the more advanced or experimental methods were not used in this study, as the data required to support them were not available for historical storms. As noted in the section titled "Overview of loss models," nine wind models, four boundary layer models, and nine damage functions were used. The specific techniques used are further documented in the NCDOI study, which along with output data from the simulations are available online at www.methaz.com/ncdoi.

\section{COMPARISON WITH OBSERVED LOSSES.}

Each technique (wind, boundary layer, damage model) is implemented in WDPEP as a Fortran90 module. During the process of creating the WDPEP program, the code for each model was manually compared with results in the literature, as well as actual storm data where appropriate. We have avoided the temptation of tuning any individual model or combination to better perform against the limited set of storm observations, preferring to leave the models to function as published.

Assessing and reporting the performance of 324 distinct models presents a challenge. Here we briefly review the performance of the models against reported claims from two recent major hurricanes, Andrew and Hugo. While most insurance data are proprietary, there has been considerable dissemination of these data over time. For example, in the report for the Sea Grant Consortium, Rosowsky et al. (1999) reported zip code-level losses from a major insurance company. Through this and other sources, such as reports to state insurance regulators, we have assembled a dataset of losses for both storms. In addition, the National Hurricane Center reports storm total (both insured and uninsured) losses for storms in their preliminary storm reports and in their "deadliest and costliest" publications (Jerrell et al. 2001). We have tested models against a variety of recent storms using the storm total losses with great success, but as the focus of this study is on insured losses, we will concentrate on the Hugo and Andrew data. Given the differences in these two storms in size and geometry, this is considered to be an adequate base. Table 5 shows the top 20 models for each storm. Note that good performance on one storm does not imply good performance on the other.

The NCDOI report cites additional simulations for Hurricanes Fran, Bertha, Floyd, Opal, Erin, and Bob. Fortunately for Atlantic basin residents, there have been few modern storms causing truly catastrophic (over $\$ 5$ billion) losses. However, this absence precludes further improving the state of the art of hurricane risk analysis. Therefore, given the fact that models are easily "tuned" to match the performance of small sets of storms, these data may be encouraging but not necessarily definitive.

During the course of the NCDOI study, Hurricane Isabel made landfall on the North Carolina coast. We took advantage of this opportunity to run the 324 (public domain) combinations of models in real time. The median of these estimates was $\$ 1.13$ billion. According to media reports, the estimated insured losses for Isabel will be approximately $\$ 1$ billion. During the 2004 season we established a Web site to make real time damage estimates based on the official forecasts available online at http://hurricane. methaz.org.

\section{COMPARISON WITH PROPRIETARY}

MODELS. Virtually all of the models used for insurance rate making are proprietary, and thus not subject to detailed evaluation or comparison. However, the state of Florida requires these proprietary modeling companies to submit the results of

\section{TABLE 4. Summary of statistical approaches.}

\begin{tabular}{|l|l|l|l|}
\hline Method & \multicolumn{1}{|c|}{$\begin{array}{c}\text { Consistency with } \\
\text { historical data }\end{array}$} & Distribution fitting & $\begin{array}{c}\text { Applicability of various } \\
\text { hurricane models }\end{array}$ \\
\hline $\begin{array}{l}\text { Historical storm set } \\
\text { estimation }\end{array}$ & $\begin{array}{l}\text { Exact match with } \\
\text { historical data }\end{array}$ & None needed & No restrictions \\
\hline Monte Carlo & $\begin{array}{l}\text { Generally no statistically } \\
\text { significant differences } \\
\text { with historical data } \\
\text { (one time effort) }\end{array}$ & $\begin{array}{l}\text { All hurricane frequencies } \\
\text { and tracks and individual } \\
\text { hurricane characteristics }\end{array}$ & $\begin{array}{l}\text { May need adjustments } \\
\text { for various models }\end{array}$ \\
\hline MLE Weibull & $\begin{array}{l}\text { Close to historical storm } \\
\text { set estimation results }\end{array}$ & Annual maxima at each site & No restrictions \\
\hline
\end{tabular}


TABLE 5. Top 20 models for Hurricane Andrew and Hugo.

\begin{tabular}{|c|cccc|cccc|}
\hline \multirow{2}{*}{ Rank } & \multicolumn{3}{|c|}{ Andrew } & \multicolumn{3}{c|}{ Hugo } \\
\cline { 2 - 9 } & Wind & Friction & Damage & Percent error* & Wind & Friction & Damage & Percent error* \\
\hline I & GE & TR & CLEMI & 0.02 & MI & TR & PT & 0.06 \\
\hline 2 & AF & AS & AUS & 0.25 & HO & CE & CLEM2 & 0.22 \\
\hline 4 & SL & TR & FRIED & 0.47 & AF & TR & ENER & 0.46 \\
\hline 5 & BR & AS & FRIED & 0.50 & HN & CE & PT & 0.49 \\
\hline 6 & RN & NO & STUB & 0.59 & SP & AS & ENER & 0.79 \\
\hline 7 & SP & CE & FRIED & 0.62 & RN & CE & FORM & 1.50 \\
\hline 8 & GE & TR & XCUB & 0.74 & AF & AS & PT & 1.83 \\
\hline 9 & MI & CE & FORM & 0.78 & MI & AS & PT & 1.84 \\
\hline 10 & AF & TR & FORM & 0.85 & HO & AS & STUB & 2.12 \\
\hline 11 & HN & TR & CLEM2 & 0.89 & AF & AS & ENER & 2.25 \\
\hline 12 & HN & NO & CLEM2 & 1.09 & RN & CE & ENER & 2.42 \\
\hline 13 & RN & CE & STUB & 1.50 & SP & TR & ENER & 2.55 \\
\hline 14 & HO & AS & AUS & 1.63 & HN & AS & XCUB & 2.59 \\
\hline 15 & SP & CE & CLEMI & 2.34 & MI & AS & STUB & 2.65 \\
\hline 16 & SL & TR & ENER & 2.35 & SL & AS & CLEM2 & 2.98 \\
\hline 17 & HN & NO & AUS & 2.43 & HN & TR & AUS & 3.17 \\
\hline 18 & BR & AS & XCUB & 2.57 & SP & TR & FORM & 3.41 \\
\hline 19 & HN & TR & FORM & 2.73 & MI & TR & ENER & 3.91 \\
\hline 20 & BR & AS & CLEMI & 3.53 & MI & TR & STUB & 4.48 \\
\hline
\end{tabular}

*Percent error is the difference between reported and model-generated loss.

controlled tests on their models as part of their approval process. These datasets, which are in the public domain and published on the Florida State Board of Administration Web site (www.sba.state.fl.us), are a rich resource for evaluating the performance of proprietary models, as well as a reference for comparing them to public domain methods. Complete details on these evaluations are available in the annual "Report of Activities," also available on the Web site. While we are confident that most, if not all, of the models used here would pass the Florida Commission on Hurricane Loss Projection Methodology (FCHLPM) standards (FCHLPM 2002), it should be noted that we did not conduct all of the tests or evaluations in the standards as many did not apply to this study. Our opinion on likely compliance is based on our own experience with audits for the FCHLPM, which emphasize a scientific literature basis for the physical models.

The major evaluation instrument of interest here is the "Form D" test from the 2002 Florida Commis- sion standards. In this evaluation, modelers are required to provide the maximum, minimum, and weighted average loss cost for each of Florida's 67 counties for various policy and construction types. Insurance companies have only recently begun to record detailed information on individual properties, such as construction type. Because of limited validation data on the performance of specific construction types, we made our comparison using the zero-deductible wood frame analysis (which is of roughly average performance) and compared the range of results of the public domain methods with the four proprietary models approved by the commission in 2003. Figure 2 shows the results of the comparison. All loss costs in this report are in losses per $\$ 1,000$ of exposure. It should be noted that our simulations used historical storm data from the entire current HURDAT dataset (1851-2002), while the proprietary modelers restricted their statistical base to the 1900-2002 time frame.

In Fig. 2, the black vertical lines reflect the range of the public domain models. The black dashes are the 


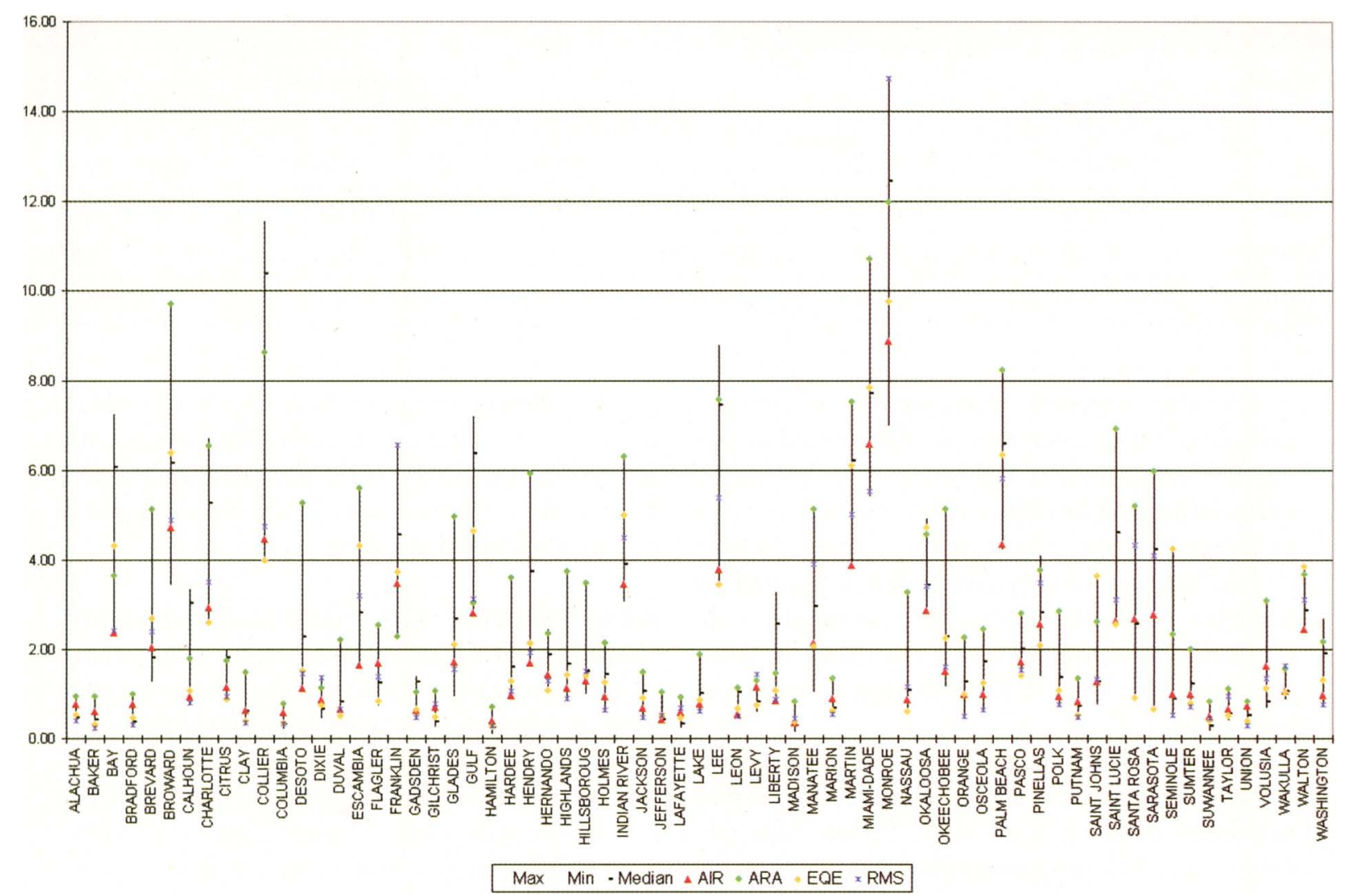

Fıg. 2. Comparison of public domain and proprietary models in Florida. Loss cost per $\$ 1000$ of exposure by county as computed by public domain and proprietary models in Florida.

medians of the public domain models, while the color-coded symbols are the results of the various proprietary models. It is comforting and interesting to note that the range of public domain model results closely mirrors the range of results provided by the proprietary methods. This is, on the whole, not surprising, given that from what has been revealed by the proprietary modelers in their publications and Florida submissions, they are using techniques based on the same published techniques as used in the public domain models.

Given the results of both the simulation of historical storm losses and the comparison with outputs of commercial models as reported to the Florida Loss Commission, we are confident in asserting that the public domain models are producing reasonable results that reflect the state of the art of hurricane loss modeling.

\section{LOSS COSTS FROM THE TOP FOUR} MODELS. A basic, implicit premise in the hurricane modeling industry (as exemplified by the proprietary modelers) is that models that capture the features of historical storms (both wind field and loss-costs agreements with actual values) will provide accurate and reliable estimates of future annual loss costs. If this assumption were true, one would think intuitively that well-performing models should produce similar loss costs. To examine this premise more closely in the context of the 324 combinations of public domain models, we extracted detailed data for the top four performing models with respect to the root-meansquare error (rmse) for all 1288 simulations against observed data (incurred losses across all states). The four leading models are given in more detail in Table 6.

These four models are relatively indistinguishable regarding rmse, although they vary as to best and worst performance on individual storms. It is interesting that the most accurately simulated storms are arguably the most extensively observed storms (certainly from a loss standpoint), while the less well observed storms, Opal and Floyd, each had unique aspects to their meteorology and losses (Opal, for the rapid collapse of the storm before and during landfall; Floyd, for the unusual flooding associated with the event that potentially distorted the wind loss figures). It is also interesting to note that none of the top four models were in the top five "best" for any single 
TABLE 6. Top four models with respect to rmse.

\begin{tabular}{|lcccccc|}
\hline $\begin{array}{l}\text { Model } \\
\text { name }\end{array}$ & Wind field & Friction & Damage & Rmse & $\begin{array}{c}\text { Best relative } \\
\text { match (storm) }\end{array}$ & $\begin{array}{c}\text { Worst relative } \\
\text { match (storm) }\end{array}$ \\
\hline Alpha & AFGWC & Trajectory & Foremost & 0.0593 & $0.01 \%$ (Andrew) & $7.50 \%$ (Opal) \\
\hline Beta & AFGWC & Trajectory & ProTeam & 0.0595 & $0.30 \%$ (Hugo) & $9.21 \%$ (Opal) \\
\hline Gamma & Rankin & Cell & Clemson2 & 0.0633 & $0.03 \%$ (Hugo) & $15.94 \%$ (Floyd) \\
\hline Delta & Standard project & ASCE-7 & ProTeam & 0.0676 & $0.40 \%$ (Hugo) & $12.33 \%$ (Floyd) \\
\hline
\end{tabular}

storm event. However, given their overall performance against observations, we feel justified in saying that any of these models does an acceptable job of reproducing observations, and are reflective of the performance obtained from proprietary models. Note that the "gamma" model is very close to being a simple baseline model-the wind model is the simplest used (Rankine), wind friction is very basic, and the damage model is a simple fit to reported damage in Hurricane Hugo.

Figure 3 provides the associated loss costs for each of the four "winners" while Fig. 4 gives details for four important counties in the state. Viewed independently, each dataset appears reasonable, demonstrating a logical relation to risk via smooth transitions, largest risks in coastal zones, and so forth.

The above maps and data may be discouraging for the users of insurance loss models. While coastal loss costs for the top two models (alpha and beta) differ by "only" $12 \%$, in the important inland area of Wake County (which contains the state capital of Raleigh) the difference is nearly a factor of 6 -the range among all four is larger. Note that these model results share common assumptions for landfall frequencies, decay rates, the exposure database, and so forth. Were differing, yet equally valid assumptions for these additional variables used, the results would probably be even more divergent. One might argue that the inland areas are less important; however, given the distribution of exposures and the premiums paid, these areas contribute significant income to insurance companies (and losses, as Hugo and more recently Isabel demonstrated).

Two points need to be made with respect the previous paragraph's perspective. First, the results from computer models are potentially a significant improvement in reliability over previous econometric approaches relying on historical losses alone. Second, the disparities at the county level across models are ameliorated to some extent by aggregating to larger domains. However, aggregation can have the effect of suggesting homogeneity of risk where, in fact, risks may be different, and given the politically charged atmosphere of insurance rate determination, large differences in loss costs created by scientifically defensible models is problematic in the public approval process (Watson et al. 2004).

\section{ASSESSMENT OF MODEL-TO-MODEL} VARIABILITY. The previous section demonstrated that seemingly equally viable models (with respect to rmse against observed losses) can produce rather different estimated loss costs. This range presents a major problem for regulators, government officials, and consumers, as the choice of model could result in premiums differing by several hundred dollars a year for a typical home. The bottom line is that the state of the art is insufficient to produce sufficiently tight groupings of results to allow users to apply model results with confidence. How best can the state of the art be improved to achieve a tighter understanding of loss costs?

Understanding the various sources of variation in this study sheds light on the critical components contributing to loss-cost results. The loss-cost maps in the previous section reveal the obvious conclusion that the expected loss costs vary spatially (Outer Banks have higher rates than the interior). Hence, we focus on individual locations as a start. The 324 model combinations represent what is known as a three-factor crossed design, with the factors being wind field (nine levels), friction (four levels), and damage (nine levels). A convenient way to display this information is a variability chart as given in Fig. 5. We are interested in how loss costs (the vertical scale on the topmost graph) vary depending on damage function (AUST, CLEM1, .. , XCUBE, see Table 3 ) of which there are nine possibilities. For each damage function, there are nine wind fields (AP, BR, . . , SP). For each damage function-wind field combination, there are four friction functions, represented by the little vertical lines in the graph. There is very little spread across the four friction factors regardless of the damage-wind field combination. For loss-cost estimation, friction does 


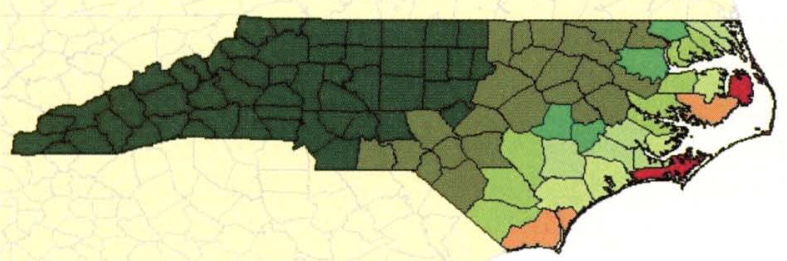

Alpha

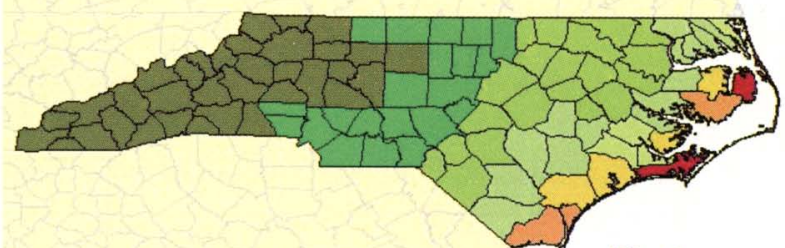

Beta
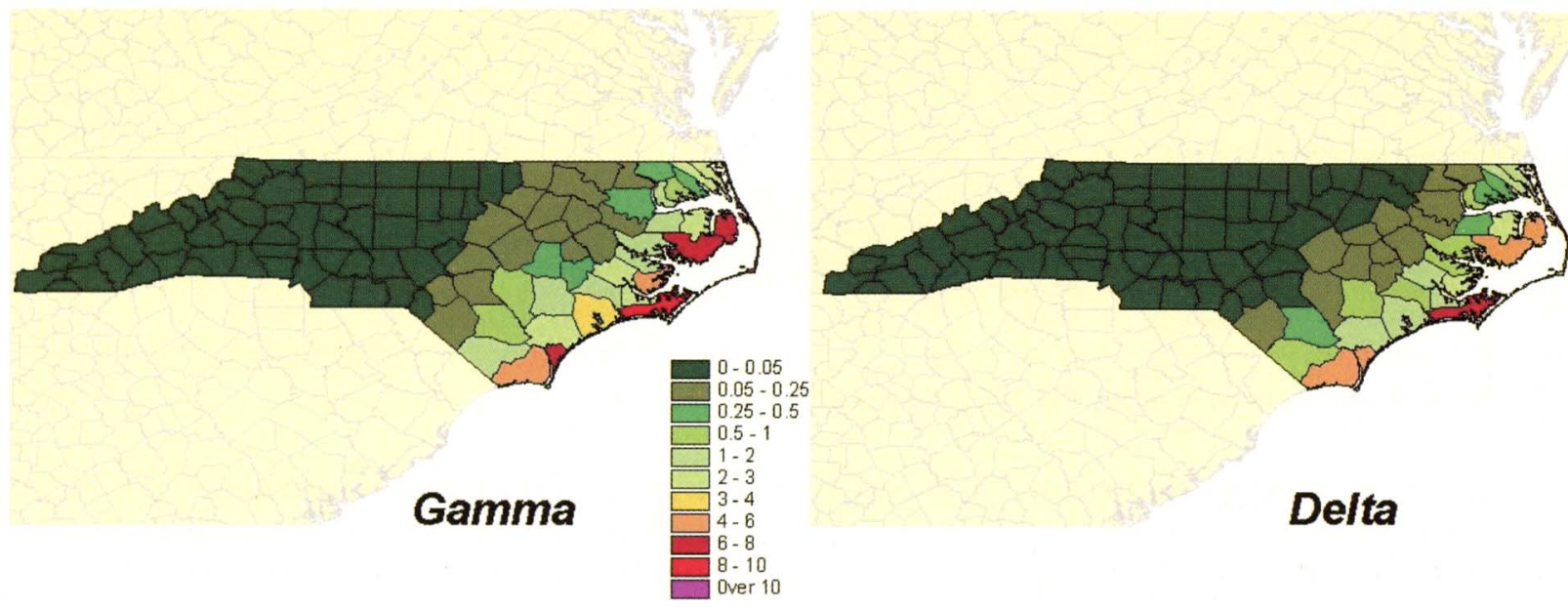

Delta

FIG. 3. Loss costs per $\$ 1,000$ for top four models identified in Table 3.

\begin{tabular}{|l|r|r|r|r|}
\hline & Dare & Brunswick & Wake & Buncome \\
\hline Alpha & 6.28 & 4.37 & 0.10 & 0.02 \\
\hline Beta & 7.03 & 5.05 & 0.59 & 0.19 \\
\hline Gamma & 7.90 & 5.26 & 0.04 & 0.01 \\
\hline Delta & 5.93 & 4.20 & 0.08 & 0.00 \\
\hline
\end{tabular}

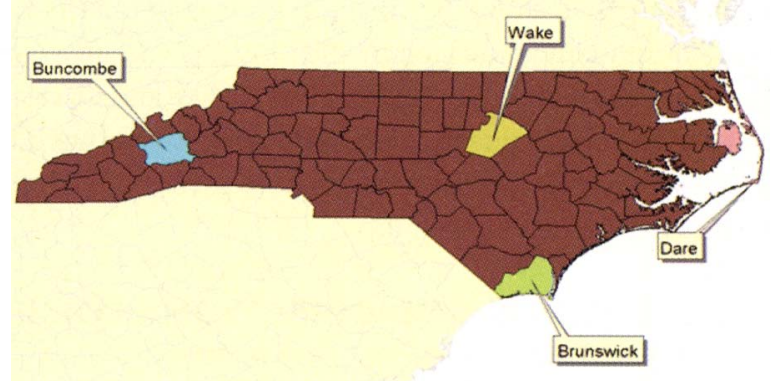

\section{Dare - outer banks Brunswick - Wilmington Wake-Raleigh Buncome-Asheville}

FIG. 4. Loss cost per $\$ I, 000$ of exposure for four counties.

not appear to be an influential factor. On the other hand, two damage functions stand out as being relatively high, namely, CLEM1 and FRID. These two also behave very similarly in conjunction with common wind fields. In fact, the patterns are quite common across all damage functions, the vertical scale, and location changing to some extent. Moving down the plot to the table labeled "variance components," a numerical summary of the components of the variation matches the visual inspection. Damage function is the primary contributor to the variation in loss costs followed by wind field. Friction (equivalent to "within" in the variance components table) is almost negligible. This result is at first surprising, given the critical factor friction plays in the performance of models on individual storms. However, upon further reflection it does make sense, as different storms deposit peak winds on a given location from different directions, 


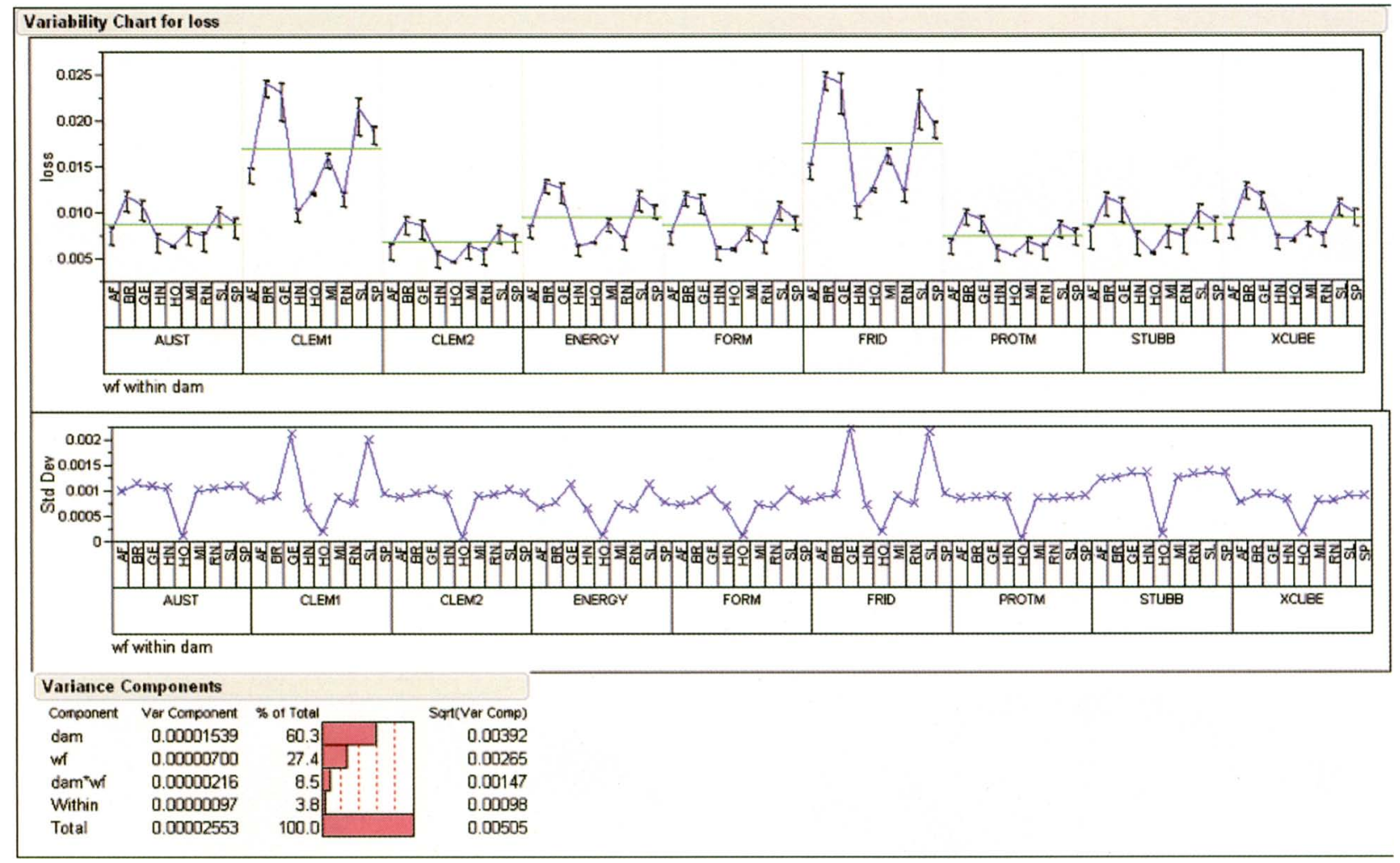

FIG. 5. Variability analysis for census BG 3802. See text for details.

thus potentially averaging out the impact of surface friction over many storms.

In the NCDOI study, many more variability charts were generated and examined. The basic pattern of damage function as the dominant source of variation and wind field as the runner-up was consistent. The standard deviation plot provides further insight, especially for the friction component (indicated by the "within" variance component). The Georgiou (1985) and Sea, Lake and Overland Surges from Hurricanes (SLOSH) wind fields have the greatest variability across friction choices; while the Holton (1992) has the least variability.

\section{CONCLUSIONS AND DIRECTIONS FOR FU-}

TURE RESEARCH. Proprietary models are currently used in the insurance industry as the basis for setting premiums and reinsurance rates for hurricane wind perils. Good-faith efforts of the modelers in their choices of components still lead to disparate loss costs across models. By considering public domain components, 324 combinations of models were used to span the range of plausible loss costs and determined that these results bracketed closely the proprietary results. The range in loss costs can be large depending on the level of aggregation (a 3-to-1or-greater ratio is not uncommon in considering the 90th to 10th percentile of results at a given site). In looking at the four "winning" models with respect to rmse across sev- eral historical storms, the subsequent loss costs diverged considerably, especially for inland areas. The dominant contributor to variation was the choice of damage function, followed by the wind field. Friction effects are relatively negligible for overall loss costs yet are highly influential for individual storms.

Damage functions are highly nonlinear: average structural damage could be $10 \%$ at $100 \mathrm{mph}, 25 \%$ at $130 \mathrm{mph}$, and $80 \%$ at $160 \mathrm{mph}$. Inaccuracies and uncertainties in the wind field propagate dramatically into the damage calculations, making improvements in damage functions unlikely in the absence of significant improvements in the understanding and modeling of the distribution of winds in hurricanes.

The extent of variance reduction from improved scientific, physical, and database improvements in conjunction with improved meteorological modeling would be beneficial to many decision analysts. What can be done to further reduce the variation in loss costs as exhibited in this study? Based on our analysis, we offer the following specific challenges to the meteorological research community.

1) Develop a more refined set of historical hurricane parameters. The models are restricted by the availability and accuracy of input conditions including radius of maximum wind, environmen- 
tal pressure, and distance to the environment. While the Tropical Prediction Center's (TPC) Automated Tropical Cyclone Forecast (ATCF) system files have this data, and are now available online, they only have detailed data since 1990 . In addition, these are not "best fit" data but are based on real-time observations. Based on our return-period analyses, it does not appear that further extending the current HURDAT data back in time, as TPC is currently doing, will necessarily reduce the variation observed in loss costs, and could in fact increase this variation if only track data and storms of uncertain intensity are included. This is not meant to disparage the reanalysis effort, which is meritorious on other grounds, but to point out that it may not help the problems discussed here. A reviewer has further suggested that the development of reliable databases on tropical cyclones ought to follow existing standards (in particular, World Meteorological Organization standards) in development, a point with which we enthusiastically agree. Along these lines, a centralized database of observed wind speeds could assist in the evaluation of different wind fields.

2) Assess the uncertainty in the estimated hurricane parameters. For example, the radius of maximum winds for a category- 4 storm that could be anywhere from 11 to $17 \mathrm{~km}$ would swamp wind field model refinements. Best-fit datasets should always incorporate an estimate of the uncertainty in each value provided, on an observation-by-observation basis. Uncertainty analyses in general ought to be a vital aspect of the next generation of models and model-to-model comparisons.

3) Wind field models have characteristic shapes and structures, which may or may not match actual storms. The available data on actual storms is piecemeal and dominated by observations over water. Improved observations (especially stormwide "snapshots") of the entire wind field, especially in a variety of boundary layers, are greatly needed.

4) Industrywide loss and damage data published in the public domain could settle some of the issues regarding disparate models fitting historical loss costs comparably. Such a disclosure may be politically difficult due to the ownership of the data by the insurance companies and their inconsistent data gathering and maintenance policies, but mechanisms to compile and distribute these data while protecting the identity of the underlying insurance companies can and should be developed, perhaps under the Department of Commerce as suggested by Changnon (2003). In any event, the lack of consistent insurance loss datasets is an inhibitor to investigating further model-to-model variation.

Reliable loss modeling has important implications for the emergency management, insurance, and reinsurance sectors, and can have profound impacts on the economy. Multibillion dollar decisions are made on the basis of these models, yet the state of the art of the technology does not lead to narrow ranges of results, even at the multicounty level of aggregation (Watson et al. 2004). Until the winds experienced by a structure can be reliably computed, improvements in damage functions are limited (due in part to the nonlinearity of damage functions). Therefore, the primary opportunities for improvement reside in the field of meteorology. Researchers in meteorology can make vital contributions to improving these models, and thus make an important contribution to improving the stability and rationality of the insurance markets and economic planning arenas.

ACKNOWLEDGMENTS. This work was supported in part by the North Carolina Department of Insurance, the Organization of American States (with funding from the U.S. Agency for International Development), and the Florida Department of Community Affairs. The views expressed in this paper are entirely the authors and may not reflect the official positions of the funding agencies.

\section{REFERENCES}

American Society of Civil Engineers, 2000: Minimum design loads for buildings and other structures. Tech. Rep. ASCE-7-98, 330 pp.

Brand, S., K. Rabe, and T. Laevastu, 1977: Parameterization characteristics of a wind-wave tropical cyclone model for the western North Pacific Ocean. J. Phys. Oceanogr., 7, 739-746.

Bretschneider, C., 1972: A non-dimensional stationary hurricane wave model. Proc. 1972 Offshore Technology Conf., Houston, TX, OTC, 30-42.

Changnon, S., 2003: Measures of economic impacts of weather extremes. Bull. Amer. Meteor. Soc., 84, 12311235.

Coastal Engineering Research Center, 1984: Shore Protection Manual. Vol. 1, U.S. Army Corps of Engineers, Washington, D.C.

Cook, N., 1985: The Designer's Guide to Wind Loading of Building Structures. Building Research Establishment, 178 pp. 
Dunion, J., C. Landsea, S. Houston, and M. Powell, 2003: A reanalysis of the surface winds for Hurricane Donna of 1960. Mon. Wea. Rev., 131, 1992-2011.

Florida Commission on Hurricane Loss Prediction Methodology, 2002: Report of Activities as of November 1, 2002. Florida State Board of Administration, 157 pp.

Foremost Insurance Co., 1996: Submission to Georgia Dept. of Insurance, Atlanta, GA, 62 pp.

Friedman, D., 1984: Natural Hazard Risk Assessment for an Insurance Program, The Geneva Papers on Risk and Insurance, $18 \mathrm{pp}$.

Georgiou, P., 1985: Design wind speeds in tropical cyclone prone regions. Ph.D. dissertation, Dept. of Civil Engineering, University of Western Ontario, 45 pp.

Holland, G., 1980: An analytic model of the wind and pressure profiles in hurricanes. Mon. Wea. Rev., 108, 1212-1218.

Holton, J., 1992: An Introduction to Dynamic Meteorology. Academic Press, 405 pp.

Hope, J., and C. Neumann, 1970: An operational technique for relating the movement of existing tropical cyclones to past tracks. Mon. Wea. Rev., 98, 11881190.

Howard, R. A., J. Matheson, and W. North, 1972: The decision to seed hurricanes. Science, 176, 1191-1201.

Jarvinen, B. R., C. Newman, and M. Davis, 1984: A tropical cyclone data tape for the North Atlantic Basin, 1886-1983: Contents, limitations, and uses. NOAA Tech. Memo NWS NHC 22, 21 pp.

Jelesnianski, C., J. Chen, and W. Shaffer, 1992: SLOSH: Sea, lake, and overland surges from hurricane phenomena. NOAA Tech. Rep. NWS 48, 71 pp.

Jerrell, J., M. Mayfield, E. Rappaport, and C. Landsea, 2001: The deadliest costliest, and most intense United States Hurricanes from 1900 to 2000 . NOAA Tech. Memo. NWS TPC-1, 30 pp.

Johnson, M. E., 1997: Caribbean storm surge return periods. Proc., Organization of American States Caribbean Disaster Mitigation Project Workshop, Kingston, Jamaica, Organization of American States, 81-95.

_ , and C. Watson Jr., 1999: Hurricane return period estimation. Preprints, 10th Symp. on Global Change Studies, Dallas, TX, Amer. Meteor. Soc., 478-479.

Landsea, C., and Coauthors, 2004a: The Atlantic hurricane database re-analysis project: Documentation for the 1851-1910 alterations and additions to the HURDAT database. Hurricanes and Typhoons: Past, Present and Future, R. J. Murnane and K.-B. Liu, Eds., Columbia University Press. [Available online at http://www.aoml.noaa.gov/hrd/hurdat/ Documentation.html.]
- - and Coauthors, 2004b: A reanalysis of Hurricane Andrew's intensity. Bull. Amer. Meteor. Soc., 85, 1699-1712.

Leicester, R., and F. Beresford, 1978: The resistance of Australian housing to wind forces. Commonwealth of Australia Dept. of Housing and Construction Rep., Australia Government Public Service, 90 pp.

Malmquist, D., and A. Michaels, 2000: Severe storms and the insurance industry. Storms, R. Pielke Jr. and R. Pielke Sr., Eds. Routledge, 54-69.

Miller, B., 1962: Characteristics of hurricanes. Science, 157, 1389-1399.

Pielke, R., Jr., C. Landsea, R. Musulin, and M. Downton, 1999: Evaluation of catastrophe models using a normalized historical record: Why it is needed and how to do it. J. Risk Insurance, 18, 177-194.

Powell, M., S. Houston, and I. Ares, 1995: Real-time damage assessment in hurricanes. Preprints, 21st Conf. on Hurricanes and Tropical Meteorology, Miami, FL, Amer. Meteor. Soc., 500-502.

Rosowsky, D., P. Sparks, and Z. Huang, 1999: Wind Field Modeling and Hurricane Hazard Analysis. SC Sea Grant Consortium, 148 pp.

Schwerdt, R., F. Ho, and R. Watkins, 1979: Meteorological criteria for standard project hurricane and probable maximum hurricane wind fields, Gulf and East Coasts of the United States. NOAA Tech. Rep. NWS 23, 79 pp.

Sill, B., T. Reinhold, and R. Kozlowski, 1997: Analysis of storm damage factors for low rise structures. Florida Commission on Hurricane Loss Projection Methodology Rep., 22 pp.

Stubbs, N., 1996: Estimation of building damage as a result of hurricanes. USDE Rep., Organization of American States, 97 pp.

Watson, C., Jr., 1995: The arbiter of storms: A high resolution, GIS based storm hazard model. Natl. Wea. Dig., 20, 2-9.

— $2002 \mathrm{a}$ : Using integrated multi-hazard numerical models in coastal storm hazard planning. Solutions for Coastal Disasters '02 Conference Proc., Reston, VA, American Society of Civil Engineers, 172-177 pp. , 2002b: Implications of climate change for modeling coastal hazards. Solutions for Coastal Disaster '02 Conference Proc., Reston, VA, American Society of Civil Engineers, 467-472.

— and M. Johnson, 2003: An assessment of computer based estimates of hurricane loss costs in North Carolina. North Carolina Department of Insurance, $34 \mathrm{pp}$.

,$- \ldots$, and M. Simons, 2004: Insurance rate filings and hurricane loss estimation models. J. Insurance Regulation, 22 (3), 39-64. 